\title{
Systolic blood pressure values might further risk-stratify the adverse outcomes of LVH in older patients with chronic kidney disease
}

\author{
Carlos R. Franco Palacios ${ }^{1 *}$, Pankaj Goyal' ${ }^{2}$ Amanda M. Thompson ${ }^{3}$ and Brent Deschaine ${ }^{4}$
}

\begin{abstract}
Background: LVH is highly prevalent in patients with CKD and is independently associated with subsequent cardiovascular events.

We hypothesized that adding systolic blood pressure values to LVH might differentiate different subgroups of patients at higher risk of cardiovascular events (CVE) and other adverse outcomes.

Methods: Retrospective cohort study of 243 patients older than 60 years with stages 1-5 pre-dialysis CKD. LVH was assessed by electrocardiogram or echocardiogram.

Results: Cardiovascular events occurred in 7 patients (10.3\%) among those with SBP $<130$ and no LVH, 8 patients (10.5\%) among those with SBP $\geq 130$ and no LVH, 7 patients (21.2\%) among those with SBP $<130$ and LVH and 25 patients (37.9\%) among those with $\mathrm{SBP} \geq 130$ and LVH.

On multivariate analyses, comparing to SBP $<130$ and no LVH, the HR for CVE in those with SBP $\geq 130$ and LVH was $4(1.75,10.3), p=0.0007 ; 2.13(0.71,6.32) p=0.16$ in those with SBP $<130$ and LVH and $1.20(0.42,3.51) p=0.72$ in those with SBP $\geq 130$ and no LVH.

No significant differences were noted in changes in renal function and mortality rates among the groups.

Conclusion: The combination of higher systolic blood pressure and LVH might identify older patients with CKD at higher risk of cardiovascular outcomes.
\end{abstract}

Keywords: Hypertension, Chronic kidney disease, Elderly, Cardiovascular disease, Outcomes, LVH

\section{Background}

Cardiovascular disease represents the main cause of morbidity and mortality in patients with chronic kidney disease (CKD).

Left ventricular hypertrophy ( $\mathrm{LVH})$ is a known manifestation of hypertensive target organ damage.

LVH is highly prevalent in patients with CKD and is already present in the early stages of the disease. Its prevalence increases with age, anemia, hypertension and lower renal function $[1,2]$.

\footnotetext{
*Correspondence: drcarlosfranco@yahoo.com

'Nephrology Department, Affiliated Community Medical Centers, Rice Memorial Hospital, 101 Willmar 274 Ave SW., Willmar, MN 56201, USA

Full list of author information is available at the end of the article
}

More advanced CKD at baseline may be associated with larger longitudinal increases in left ventricular mass and volume and greater deterioration in diastolic function [3].

On the other hand, more severe LVH is associated with kidney function decline and progression to dialysis $[4,5]$.

In patients with CKD, LVH and other echocardiographic parameters (including low EF) are independently associated with subsequent cardiovascular events $[6,7]$.

Because of the above, treating hypertension is of paramount importance in CKD populations. At the same time, the ideal blood pressure target in these patients is a subject of controversy. Retrospective studies in older patients with CKD suggest mortality is increased for systolic blood pressures (SBP) higher and lower than 130-139 $\mathrm{mmHg}$ and DBP of 60-79 $\mathrm{mmHg}[8]$. 
The objective of this study was to assess the prognostic value of combining $\mathrm{LVH}$ data with clinical data (SBP) as markers of adverse outcomes in older patients with CKD.

Our hypothesis is that adding systolic blood pressure values to $\mathrm{LVH}$ might help differentiate different subgroups of patients at higher risk of adverse outcomes.

\section{Methods}

After obtaining approval from the Rice Memorial Hospital Institutional Review Board (Willmar MN), a retrospective cohort study of 243 patients older than 60 years with stages 1-5 pre-dialysis CKD was carried out. These patients were seen in a Nephrology clinic between January of 2013 and November of 2015.

Since prior studies in older patients with CKD suggest that mortality is lower for a SBP around $130 \mathrm{mmHg}$, we decided to use this value as reference [8].

$C K D$ was defined as evidence of structural or functional kidney abnormalities (abnormal urinalysis, imaging studies, or histology) that persisted for at least 3 months, with or without a decreased glomerular filtration rate (GFR), as defined by a GFR of less than $60 \mathrm{~mL} / \mathrm{min}$ per $1.73 \mathrm{~m} 2$.

\section{Exclusion criteria}

Patients on renal replacement therapy, history of organ transplant, patients younger than 60 years of age, patients with a clinical diagnosis of congestive heart failure (CHF) at baseline, patients without LVH data.

\section{Variables collected}

Demographics, comorbidities, LVH assessment by electrocardiogram (ECG) or echocardiogram and laboratory data at baseline and during follow up.

\section{Primary outcome: new cardiovascular events}

Cardiovascular events ( $C V E$ ) were defined as the composite of new episodes of acute coronary event, decompensated heart failure and cerebrovascular accident (stroke, transient ischemic attack) during the follow up period.

\section{Secondary outcomes}

End stage renal disease requiring dialysis; changes in GFR; all-cause mortality. The cause of death was obtained from the medical records or death certificates.

\section{Estimation of blood pressure}

Office systolic blood pressures (SBP) and diastolic blood pressures (DBP) were measured with an automated device, using an adult cuff, with the patient in a seated position. Pulse pressure was determined by subtracting the DBP from the SBP. In the calculation of the mean blood pressure, we used blood pressures collected during regular visits to maintain consistency among all participants. A median of 18 [10, 28] blood pressure readings were obtained for each patient.

\section{Definition of LVH}

The patients included in the study had LVH evaluation either by echocardiogram or electrocardiogram (ECG), these reports were obtained from the medical chart. A patient was deemed to have LVH if there was a report (either by ECG or echocardiogram) diagnosing this condition. LVH by echocardiogram is defined as a LVMI (left ventricular mass index) $\geq 150 \mathrm{~g} / \mathrm{m}^{2}$ [9]

LVH by electrocardiogram is defined by a Sokolow-Lyon voltage amplitude of (SV1 + RV5 or RV6) $\geq 3.5 \mathrm{mV}$ and/or a Cornell voltage of $(\mathrm{SV} 3+\mathrm{RaVL})>2.8 \mathrm{mV}$.

\section{Glomerular filtration rate (GFR)}

GFR was estimated by the four-variable Modification of Diet in Renal Disease formula (MDRD) [10].

\section{Estimation of proteinuria}

Random urine albumin (albumin-to-creatinine ratio, expressed as $\mathrm{mg} / \mathrm{g}$ ) or total protein (protein-to-creatinine ratio, expressed as $\mathrm{mg} / \mathrm{g}$ ) were obtained after reviewing the medical chart.

\section{Statistical analyses}

Data are presented as mean and standard deviation if normally distributed and median [25\% and $75 \%$ percentiles] or range if not. For parametric data, differences in the mean were compared by ANOVA. For highly skewed data, the Wilcoxon- Kruskal Wallis Test was used.

Differences in proportions were assessed by the Chi square or Fisher's exact test.

Survival curves were generated using the KaplanMeier method. Cox proportional hazards models were used to study associations and adjust for confounding factors.

$P$ values lower $\leq 0.05$ were considered statistically significant. All the analyses were performed using JMP statistical software version 11.2.0 (SAS Campus Drive, Cary, NC).

\section{Results}

The baseline characteristics are depicted in Table 1.

Echocardiographic information was present in 160 patients. Electrocardiographic information was present in 84 patients. Whenever the two were present, the echocardiographic data was used for analyses.

Primary and secondary outcomes are reported in Table 2. During the follow up period (median 2.5 years, range 0.02-2.8) there were 47 cardiovascular events and 13 deaths. The incidence of cardiovascular events was higher in those patients with $\mathrm{LVH}$, especially in those with a SBP $\geq 130 \mathrm{mmHg}$ (Fig. 1). 
Table 1 Baseline characteristics

\begin{tabular}{|c|c|c|c|c|c|}
\hline & $\begin{array}{l}\mathrm{SBP}<130 \text { and LVH } \\
N=33\end{array}$ & $\begin{array}{l}\text { SBP } \geq 130 \text { and LVH } \\
N=66\end{array}$ & $\begin{array}{l}\text { SBP }<130 \text { and no LVH } \\
N=68\end{array}$ & $\begin{array}{l}\text { SBP } \geq 130 \text { and no LVH } \\
N=76\end{array}$ & $P$ value \\
\hline Age, years, mean $\pm S D$ & $76 \pm 7.2$ & $77.4 \pm 8.9$ & $72.8 \pm 8.2$ & $72.9 \pm 8.2$ & 0.002 \\
\hline Caucasian, \% & $31(93.9)$ & 65 (98.5) & $67(98.5)$ & $71(93.4)$ & 0.38 \\
\hline Men, \% & $15(45.4)$ & $33(50)$ & $30(44.1)$ & $36(47.4)$ & 0.92 \\
\hline Obesity, \% & $23(69.7)$ & $31(47)$ & $38(55.8)$ & $38(50)$ & 0.15 \\
\hline Cancer, \% & $7(21.2)$ & $24(36.4)$ & $13(19.2)$ & $14(18.4)$ & 0.05 \\
\hline Ejection fraction, mean $\pm \mathrm{SD}^{*}$ & $61 \pm 7.2$ & $60 \pm 7.7$ & $58 \pm 7.8$ & $61 \pm 8.8$ & 0.35 \\
\hline$C A D, \%$ & $12(36.3)$ & $22(33.3)$ & $21(30.9)$ & $11(14.5)$ & 0.02 \\
\hline CVA, \% & $1[3]$ & $7(10.6)$ & $4(5.9)$ & $5(6.6)$ & 0.51 \\
\hline DM, \% & $18(54.5)$ & $32(48.5)$ & $32(47)$ & $38(50)$ & 0.91 \\
\hline HTN, \% & $29(87.9)$ & $62(93.9)$ & $64(94.1)$ & $71(93.4)$ & 0.71 \\
\hline A fib, $\%$ & $8(24.2)$ & $11(16.7)$ & $9(13.2)$ & $10(13.1)$ & 0.49 \\
\hline Hyperlipidemia, \% & $24(72.7)$ & $41(62.1)$ & $55(80.9)$ & $56(73.7)$ & 0.11 \\
\hline Pulmonary disease, $\%$ & $10(30.3)$ & $16(24.2)$ & $13(19.1)$ & $22(28.9)$ & 0.49 \\
\hline Chronic liver disease, \% & $1[3]$ & $4[6]$ & $5(7.3)$ & $2(2.6)$ & 0.52 \\
\hline ACEls, \% & $17(51.5)$ & $32(48.5)$ & $29(42.6)$ & $39(51.3)$ & 0.73 \\
\hline ARBs, $\%$ & $4(12.1)$ & $16(24.2)$ & $9(13.2)$ & $15(19.7)$ & 0.29 \\
\hline Calcium channel blockers, \% & $7(21.2)$ & $29(43.9)$ & $21(30.9)$ & $35(46)$ & 0.03 \\
\hline Beta blockers, \% & $21(63.6)$ & $46(69.7)$ & $38(55.9)$ & $35(46)$ & 0.03 \\
\hline Thiazide diuretics, \% & $13(39.4)$ & $29(43.9)$ & $29(42.6)$ & $34(44.7)$ & 0.96 \\
\hline Loop diuretics, \% & $11(33.3)$ & $21(31.8)$ & $19(27.9)$ & 24 (31.6) & 0.93 \\
\hline K sparing diuretics, \% & $2[6]$ & $1(1.52)$ & $9(13.2)$ & $3(3.95)$ & 0.03 \\
\hline Clonidine, \% & $0(0)$ & $4[6]$ & $1(1.5)$ & $3(3.95)$ & 0.32 \\
\hline Vasodilators, \% & $2[6]$ & $17(25.8)$ & $7(10.3)$ & $5(6.6)$ & 0.004 \\
\hline $\mathrm{SBP}$ mmHg, mean $\pm \mathrm{SD}$ & $123.9 \pm 4.13$ & $140.5 \pm 8$ & $122 \pm 5.3$ & $139.3 \pm 8.3$ & $<0.0001$ \\
\hline $\mathrm{DBP} \mathrm{mmHg}$, mean $\pm \mathrm{SD}$ & $69.7 \pm 5.52$ & $73.1 \pm 7.32$ & $70.9 \pm 5.4$ & $74.7 \pm 6.6$ & 0.0002 \\
\hline PTH pg/mL, median [IQR] & $59[35,83]$ & $56[42,82]$ & $67[36,92]$ & $65[45,96]$ & 0.81 \\
\hline Hemoglobin $\mathrm{g} / \mathrm{dL}$, mean $\pm \mathrm{SD}$ & $13 \pm 1.44$ & $12.4 \pm 1.89$ & $12.7 \pm 1.66$ & $13 \pm 1.84$ & 0.13 \\
\hline Phosphorus mg/dL, mean \pm SD & $3.35 \pm 0.43$ & $4 \pm 3.28$ & $3.46 \pm 0.66$ & $3.43 \pm 0.64$ & 0.31 \\
\hline Bicarbonate $\mathrm{mEq} / \mathrm{L}$, mean $\pm \mathrm{SD}$ & $27.9 \pm 2.96$ & $27.2 \pm 2.94$ & $26.4 \pm 3.32$ & $26.9 \pm 3.12$ & 0.13 \\
\hline 25-Vitamin D ng/mL, median [IQR] & $31.8[23,43]$ & $36.9[26,48.7]$ & $38.7[21.3,48.7]$ & $28.9[19.8,48.8]$ & 0.54 \\
\hline Albumin $\mathrm{g} / \mathrm{dL}$, mean $\pm \mathrm{SD}$ & $4 \pm 0.30$ & $4 \pm 0.31$ & $4 \pm 0.36$ & $4.1 \pm 0.32$ & 0.36 \\
\hline Baseline GFR, mean \pm SD & $48.2 \pm 18.1$ & $45 \pm 18.8$ & $47.6 \pm 2.3$ & $53.3 \pm 2.1$ & 0.06 \\
\hline Proteinuria, mg/g, median [IQR] & $100[7,214]$ & $100[46,303]$ & $74.4[8.4,104]$ & $100[16.7,333]$ & 0.01 \\
\hline
\end{tabular}

IQR interquartile range, GFR glomerular filtration rate (cc/min/BSA), SBP systolic blood pressure, DBP diastolic blood pressure

*EF data was obtained in 146 patients

Table 2 Primary and secondary outcomes

\begin{tabular}{|c|c|c|c|c|c|}
\hline & $\mathrm{SBP}<130$ and $\mathrm{LVH}$ & $\mathrm{SBP} \geq 130$ and LVH & $\mathrm{SBP}<130$ and no LVH & $\mathrm{SBP} \geq 130$ and no LVH & $P$ value \\
\hline CVE, \% & $7(21.2)$ & $25(37.9)$ & $7(10.3)$ & $8(10.5)$ & $<0.0001$ \\
\hline Death, \% & $3(9)$ & $5(7.58)$ & $4(5.9)$ & $1(1.32)$ & 0.25 \\
\hline Changes in GFR during follow up (cc/min/BSA) & $-5.27 \pm 9.48$ & $-3.57 \pm 12.1$ & $-5 \pm 15.4$ & $-7.7 \pm 13.2$ & 0.31 \\
\hline ESRD, \% & $1(3)$ & $4(6)$ & 0 & $2(2.63)$ & 0.22 \\
\hline
\end{tabular}

$\overline{C V E}$ cardiovascular events, BSA body surface area, ESRD end stage renal disease, GFR glomerular filtration rate 


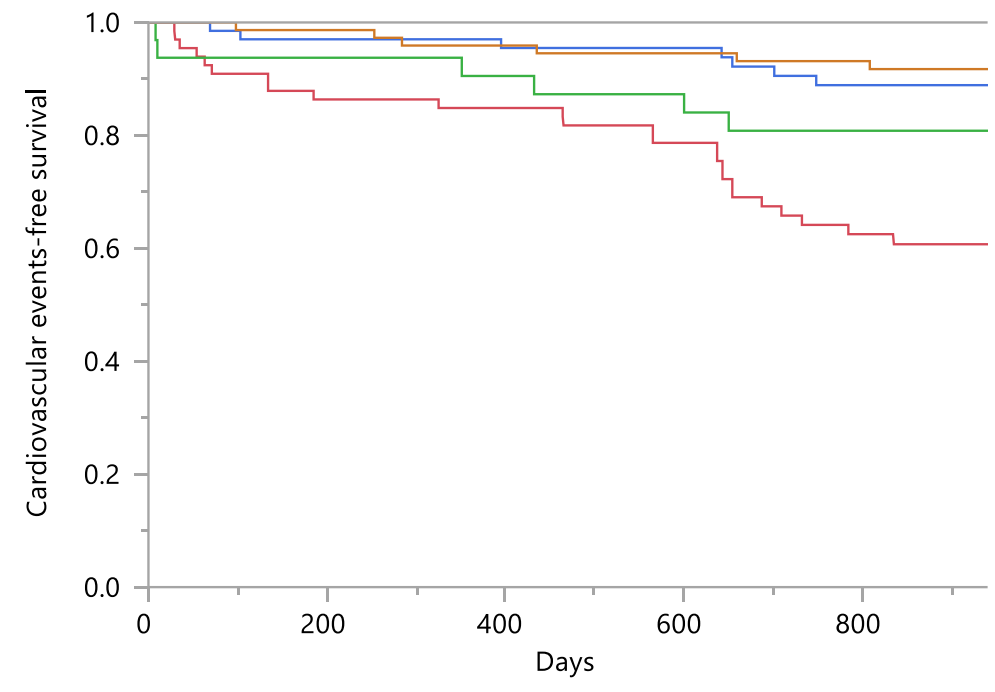

$$
\begin{array}{l|l}
-0 & \text { LVH and SBP higher than } 130 \\
-1 & \text { LVH and SBP lower than } 130 \\
-2 & \text { No LVH and SBP lower than } 130 \\
-3 & \text { No LVH and SBP higher than } 130
\end{array}
$$

Log-Rank $p<0.0001$

Wilcoxon $p<0.0001$

Fig. 1 Kaplan-Meier analyses of cardiovascular event-free survival according to LVH and SBP

Comparing to $\mathrm{SBP}<130$ and no $\mathrm{LVH}$ the unadjusted HRs for CVE in those with $\mathrm{SBP} \geq 130$ and LVH was 4 (1.82, 10), $p=0.0003$; $2.18(0.74,6.39), p=0.14$ in those with $\mathrm{SBP}<130$ and LVH and $0.96(0.34,2.74) p=0.94$ in those with $\mathrm{SBP} \geq 130$ and no LVH.

On multivariate analyses, after adjusting for confounding factors, the association of LVH and SBP $\geq 130$ with CVE remained significant (Table 3).

No significant differences were noted in changes in renal function and mortality rates among the groups, although the number of events was fairly small to make conclusions.

\section{Discussion}

In this study, we found the combination of achieved systolic blood pressure with the presence of LVH (either by ECG or Echocardiogram) might stratify the risk of CVE

Table 3 Multivariate model for cardiovascular events

\begin{tabular}{lll}
\hline & $H R(95 \% C l)$ & $P$ value \\
\hline SBP $<130$ and $L^{*} H^{*}$ & $2.13(0.71,6.32)$ & 0.16 \\
SBP $\geq 130$ and $\mathrm{LVH}^{*}$ & $4(1.75,10.3)$ & 0.0007 \\
$\mathrm{SBP} \geq 130$ and no $\mathrm{LVH}^{*}$ & $1.20(0.42,3.51)$ & 0.72 \\
\hline *Using SBP $<130$ and no $\mathrm{LVH}$ as comparison. Cox models were adjusted for \\
age, CAD, CVA, beta blocker use, vasodilator use, atrial fibrillation, obesity
\end{tabular}

among older patients with CKD. Furthermore, there appears to be a graded risk, with worse outcomes in those with a SBP $\geq 130$ and LVH vs those with a lower SBP and those without LVH.

Higher blood pressure, greater body mass index (BMI), intravascular expansion, advancing age and male gender are associated with an abnormal left ventricular geometry. This cardiac hypertrophy ultimately leads to activation of metabolic pathways that increase extracellular matrix production leading to fibrosis. Fibrosis leads to reduced contractility with myocardial wall stiffening, systolic and diastolic dysfunction, cardiomyopathy, and congestive heart failure. Changes in cardiac remodeling might be fluid, with some patients reversing to normal geometry, especially with optimal blood pressure control [11-14].

Other principles in the treatment of LVH in CKD patients include treatment of the anemia and secondary hyperparathyroidism.

Unfortunately we did not have enough data to study LV geometry and other echocardiographic parameters in this study. Other studies have found that CV event-free survival is significantly worse in the presence of concentric LVH and eccentric LVH [15].

There is some evidence that a concentric pattern (vs eccentric) portends a worse cardiovascular prognosis. 
Others suggest that LVH by itself, regardless of the geometry is associated with worse renal and cardiovascular outcomes $[16,17]$.

The association of hypertension and adverse outcomes has been well demonstrated. In this study we found no difference in survival among the groups, although the number of events is fairly small and definite conclusions cannot be reached.

In the SPRINT trial, aiming for a SBP lower than $120 \mathrm{~mm} \mathrm{Hg}$, as compared with less than $140 \mathrm{~mm} \mathrm{Hg}$ was associated with lower rates of heart failure events, cardiovascular deaths and total deaths [18].

On the other hand, retrospective studies have shown increased mortality with lower blood pressures in the elderly. Kovesdy et al found that patients with a SBP of 130 to $159 \mathrm{~mm} \mathrm{Hg}$ combined with a DBP of 70 to $89 \mathrm{~mm}$ $\mathrm{Hg}$ had the lowest adjusted mortality rates, comparing to those with higher or lower BP readings [19].

In 21,000 patients older than 65 years with stage 3-5 CKD not yet on dialysis there was increased mortality with a baseline SBP $<120 \mathrm{mmHg}$ comparing to a SBP between 131-140 mmHg. A SBP higher $>140 \mathrm{mmHg}$ was associated with increased mortality only in the younger patients with CKD [20].

We believe the discrepancy about optimal blood pressure targets in older patients might be related to the presence of $\mathrm{CHF}$, since hypotension in this setting has been associated with reduced survival [21-24].

In this study, we excluded patients with a clinical diagnosis of CHF at baseline, so our findings cannot be applied to those patients with CKD and underlying CHF.

In a recent paper we have found that a low SBP (less than $120 \mathrm{mmHg}$ ) was associated with worse survival in patients with CKD, nonetheless that patient population had more cardiovascular comorbidities at baseline (especially CHF). Based on our current findings we think studies evaluating the optimal BP target in older patients with CKD might need to differentiate among patients with and without heart failure and LVH [25].

Although this was an observational study, the follow up was extensive, given the unique geographical characteristics of this population. Most patients receive their care in one of two local clinics and are admitted to one or two hospitals which share electronic medical records. This allows for close follow up of outcomes of interest.

Among the limitations of this study we cite the retrospective design, small number of patients, lack of significant number of minorities, inability to assess for reversibility of LVH changes, use of ECG and echocardiographic criteria together, although in CKD patients $\mathrm{LVH}$ on electrocardiogram is associated with a higher increase in $\mathrm{CV}$ mortality than other traditional risk factors [26].

\section{Conclusion}

The combination of higher systolic blood pressure and LVH might identify older patients with CKD at higher risk of cardiovascular outcomes. These results should be confirmed with larger studies.

\section{Acknowledgements}

Not applicable.

Funding

None.

\section{Availability of data and material}

Yes. Data is available in a database from the corresponding author on reasonable request.

\section{Authors' contributions}

CRFP: research plan, statistics, data collection and manuscript writing. PG: manuscript writing and data collection. BD: manuscript writing.

AMT: Manuscript writing. All authors read and approved the final manuscript.

\section{Competing interests}

The authors declare that they have no competing interests.

Consent for publication

Not applicable. No individual data in any form is disclosed.

Ethics approval and consent to participate

The study was approved by the Rice Memorial Hospital Institutional Review Board. This was a retrospective study.

\section{Author details}

${ }^{1}$ Nephrology Department, Affiliated Community Medical Centers, Rice Memorial Hospital, 101 Willmar 274 Ave SW., Willmar, MN 56201, USA.

${ }^{2}$ Hospital Medicine Department, Affiliated Community Medical Centers. Rice Memorial Hospital, Willmar, MN, USA. ${ }^{3}$ Pharmacy Department, Rice Memorial Hospital, Willmar, MN, USA. ${ }^{4}$ University of Oklahoma, Cardiac Catheterization Laboratory, Oklahoma, USA.

Received: 21 July 2016 Accepted: 8 November 2016

Published online: 23 November 2016

References

1. Paoletti E, Bellino D, Cassottana P, Rolla D, Cannella G. Left ventricular hypertrophy in nondiabetic predialysis CKD. Am J Kidney Dis. 2005;46(2):320-7.

2. Levin A, Singer J, Thompson CR, Ross H, Lewis M. Prevalent left ventricular hypertrophy in the predialysis population: identifying opportunities for intervention. Am J Kidney Dis. 1996;27(3):347-54.

3. Cai QZ, Lu XZ, Lu Y, Wang AY. Longitudinal changes of cardiac structure and function in CKD (CASCADE study). J Am Soc Nephrol. 2014;25(7):1599-608.

4. Chen SC, Su HM, Hung CC, Chang JM, Liu WC, Tsai JC, et al. Echocardiographic parameters are independently associated with rate of renal function decline and progression to dialysis in patients with chronic kidney disease. Clin J Am Soc Nephrol. 2011;6(12):2750-8.

5. Park M, Shlipak MG, Katz R, Agarwal S, Ix JH, Hsu CY, et al. Subclinical cardiac abnormalities and kidney function decline: the multi-ethnic study of atherosclerosis. Clin J Am Soc Nephrol. 2012;7(7):1137-44.

6. Peterson GE, de Backer T, Contreras G, Wang X, Kendrick C, Greene T, et al. Relationship of left ventricular hypertrophy and diastolic function with cardiovascular and renal outcomes in African Americans with hypertensive chronic kidney disease. Hypertension. 2013;62(3):518-25.

7. Chen SC, Chang JM, Liu WC, Huang JC, Tsai JC, Lin MY, et al. Echocardiographic parameters are independently associated with increased cardiovascular events in patients with chronic kidney disease. Nephrol Dial Transplant. 2012;27(3):1064-70.

8. Sim JJ, Shi J, Kovesdy CP, Kalantar-Zadeh K, Jacobsen SJ. Impact of achieved blood pressures on mortality risk and end-stage renal disease among a large, diverse hypertension population. J Am Coll Cardiol. 2014;64(6):588-97. 
9. Levy D, Savage DD, Garrison RJ, Anderson KM, Kannel WB, Castelli WP. Echocardiographic criteria for left ventricular hypertrophy: the Framingham Heart Study. Am J Cardiol. 1987;59(9):956-60.

10. Levey AS, Coresh J, Greene T, Stevens LA, Zhang YL, Hendriksen S, et al. Using standardized serum creatinine values in the modification of diet in renal disease study equation for estimating glomerular filtration rate. Ann Intern Med. 2006;145(4):247-54.

11. Lieb W, Gona P, Larson MG, Aragam J, Zile MR, Cheng S, et al. The natural history of left ventricular geometry in the community: clinical correlates and prognostic significance of change in LV geometric pattern. JACC Cardiovasc Imaging. 2014;7(9):870-8.

12. Gerdts E, Cramariuc D, de Simone G, Wachtell K, Dahlof B, Devereux RB. Impact of left ventricular geometry on prognosis in hypertensive patients with left ventricular hypertrophy (the LIFE study). Eur J Echocardiogr. 2008:9(6):809-15.

13. Dahlof B, Pennert K, Hansson L. Reversal of left ventricular hypertrophy in hypertensive patients. A metaanalysis of 109 treatment studies. Am J Hypertens. 1992;5(2):95-110.

14. Di Lullo L, Gorini A, Russo D, Santoboni A, Ronco C. Left ventricular hypertrophy in chronic kidney disease patients: from pathophysiology to treatment. Cardiorenal Med. 2015;5(4):254-66.

15. Eckardt KU, Scherhag A, Macdougall IC, Tsakiris D, Clyne N, Locatelli F, et al. Left ventricular geometry predicts cardiovascular outcomes associated with anemia correction in CKD. J Am Soc Nephrol. 2009:20(12):2651-60.

16. Muiesan ML, Salvetti M, Monteduro C, Bonzi B, Paini A, Viola S, et al. Left ventricular concentric geometry during treatment adversely affects cardiovascular prognosis in hypertensive patients. Hypertension. 2004:43(4):731-8.

17. Paoletti E, De Nicola L, Gabbai FB, Chiodini P, Ravera M, Pieracci L, et al. Associations of left ventricular hypertrophy and geometry with adverse outcomes in patients with CKD and hypertension. Clin J Am Soc Nephrol. 2016;11(2):271-9.

18. Group SR, Wright Jr JT, Williamson JD, Whelton PK, Snyder JK, Sink KM, et al. A randomized trial of intensive versus standard blood-pressure control. N Engl J Med. 2015;373(22):2103-16.

19. Kovesdy CP, Bleyer AJ, Molnar MZ, Ma JZ, Sim JJ, Cushman WC, et al. Blood pressure and mortality in U.S. veterans with chronic kidney disease: a cohort study. Ann Intern Med. 2013;159(4):233-42.

20. Weiss JW, Peters D, Yang X, Petrik A, Smith DH, Johnson ES, et al. Systolic BP and mortality in older adults with CKD. Clin J Am Soc Nephrol. 2015;10(9):1553-9.

21. Buiciuc O, Rusinaru D, Levy F, Peltier M, Slama M, Leborgne L, et al. Low systolic blood pressure at admission predicts long-term mortality in heart failure with preserved ejection fraction. J Card Fail. 2011;17(11):907-15.

22. Montero-Perez-Barquero M, Flather M, Roughton M, Coats $\mathrm{A}$, Bohm M, Van Veldhuisen DJ, et al. Influence of systolic blood pressure on clinical outcomes in elderly heart failure patients treated with nebivolol: data from the SENIORS trial. Eur J Heart Fail. 2014;16(9):1009-15.

23. Rosman Y, Kopel E, Shlomai G, Goldenberg I, Grossman E. The association between admission systolic blood pressure of heart failure patients with preserved systolic function and mortality outcomes. Eur J Intern Med. 2015;26(10):807-12.

24. Lee TT, Chen J, Cohen DJ, Tsao L. The association between blood pressure and mortality in patients with heart failure. Am Heart J. 2006;151(1):76-83.

25. Franco Palacios CR, Haugen EN, Thompson AM, Rasmussen RW, Goracke N, Goyal P. Clinical outcomes with a systolic blood pressure lower than $120 \mathrm{mmHg}$ in older patients with high disease burden. Ren Fail. 2016;1-6.

26. Shlipak MG, Fried LF, Cushman M, Manolio TA, Peterson D, Stehman-Breen C, et al. Cardiovascular mortality risk in chronic kidney disease: comparison of traditional and novel risk factors. JAMA. 2005;293(14):1737-45.

\section{Submit your next manuscript to BioMed Central and we will help you at every step:}

- We accept pre-submission inquiries

- Our selector tool helps you to find the most relevant journal

- We provide round the clock customer support

- Convenient online submission

- Thorough peer review

- Inclusion in PubMed and all major indexing services

- Maximum visibility for your research

Submit your manuscript at www.biomedcentral.com/submit
Biomed Central 